\title{
O SUPERANTÍTESE \\ OBSERVAÇÕES SOBRE A CONDIÇÃO RETÓRICA DO SUPERMAN
}

Rafael Viegas*

RESUMO: O artigo é uma breve investigação dos problemas gerados pela disposição antitética dos elementos formadores do mito de origem do Superman. Apesar de se tratar de uma narrativa tardia, ela acabou dando consistência a uma interface dúbia do herói: uma excepcional redenção do americano médio.

Palavras-chave: Superman; Retórica; Antítese; Super-herói; Cultura de massa

\section{SUPERANTITHESIS SOME REMARKS ON SUPERMAN'S RHETORIC NATURE}

\begin{abstract}
This paper is a brief investigation regarding the problems generated by the antithetical disposition in the myth of Superman's origin. Despite being a late narrative, this myth gives consistency to a dubious interface of the hero: an exceptional redemption of the average American.
\end{abstract}

Keywords: Superman; Rhetoric; Antithesis; Super hero; Mass culture

"Enquanto um distante planeta é destruído pela decrepitude, um cientista põe seu bebê em uma espaçonave

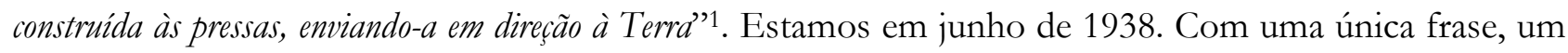
único quadro e uma contraposição (o velho planeta decrépito versus o bebê viajante), o futuro Superman sai voando de Krypton e inicia a Época de Ouro da nova Idade dos Heróis².

Os jogos de oposições são uma das principais marcas da caracterização retórica do Homem de Aço e gostaria de passar em revista, brevemente, como esse tipo de estrutura, presente já em seu mitema de origem, fundamenta seu desenvolvimento posterior.

\footnotetext{
* Rafael Viegas é Doutor em Saúde Coletiva (IMS-UERJ) e em Letras (FL-UFRJ), e atualmente pós-doutorando em Filosofia (PNPD-Capes) no PFI-UFF. ORCID: 0000-0002-8432-1957. O autor agradece a leitura preliminar e as sugestões de Luiz César de Sá (HIS-UnB).

1 "As a distant planet was destroyed by old age, a scientist placed his infant son within a hastily devised space-ship, launching it toward Earth?" (SIEGEL, Jerome \& SHUSTER, Joe. Superman. In: Action Comics \#1, 1938, p. 1).

2 "Época de Ouro" [Golden Age] é como a crítica especializada se refere ao período que vai de 1938 - época de publicação das primeiras histórias de Superman, pela Detective Comics (posteriormente abreviada como DC Comics), e do Capitão Marvel, pela Fawcett Comics - até meados da década de 1950. Seu fim é geralmente definido pela promulgação do Comic Code Authority (CCA) e pela subsequente criação da CMAA (Comics Magaz̨ine Association of America), entidade autorreguladora dos editores de quadrinhos, que tinha por principal atribuição a observância do Comic Code. O CCA surgiu por conta da repercussão de um livro do psiquiatra Fredric Wertham, Seduction of the Innocent (1954), cuja tese principal mostrava os quadrinhos como máinfluência intelectual e como incitamento à delinquência juvenil.
} 
Nesta versão simplificada de 1938, não temos ainda os elementos que compõem a versão mais conhecida de seu mito de origem, mas ela será elaborada alguns anos depois, contendo uma narrativa muito mais dramática - que é o que nos interessa mais particularmente aqui ${ }^{3}$. Nas reelaborações posteriores do mitema de origem, a cena originária é arrasadora pelo intenso contraste, misturando o nascimento ao desaparecimento, a boa nova à despedida, a canção de ninar ao thrēnos (à lamentação, ao canto fúnebre). $\mathrm{Na}$ iminência de um cataclismo planetário, Jor-L (mais tarde, a grafia se estabilizou em Jor-El), o maior cientista de Krypton ${ }^{4}$ (planeta a cerca de 27 anos-luz de nosso sistema solar 5 ), envia à Terra o que seria, virtualmente, o único sobrevivente de sua raça, prestes a desaparecer - seu próprio filho, Kal-L (Kal-El) ${ }^{6}$. Jor-El, o pai, self inabalável construído pelas certezas puras da Ciência, calculando uma rota segura para a espaçonave; Lara, a mãe, em lágrimas, envolvendo o filho em mantas protetoras; as grandes placas tectônicas de Krypton se esfacelando; os gritos de pavor de seus arrogantes cidadãos, agora que compreendem a inevitabilidade do fim (os idiotas zombaram desse fim apocalíptico, que, até então, era certeza absoluta apenas na cabeça privilegiada de seu maior cientista), cortando o ar em todas as direções? ${ }^{7}$.

Enquanto Krypton entra em convulsões intestinais apocalípticas, uma pequena espaçonave (em algumas versões, uma estrutura de rocha e/ou metal) é expelida rumo ao espaço infinito. Confortavelmente envolvido em seu aparentemente frágil casulo extraterrestre, o pequeno Kal-El

${ }^{3}$ Sabe-se hoje, porém, que Siegel e Shuster simplificaram a história propositalmente, ou por razões comerciais, pois fizeram circular, em 1939, de maneira não oficial, uma versão completa dos acontecimentos preliminares da saída de Kal-El de Krypton.

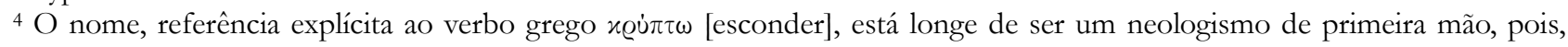
como sabemos, Krypton é também, tal como usado em inglês, o nome de um gás nobre, descoberto em 1898 pelos químicos William Ramsay e Morris Travers como resultado residual da evaporação do ar liquefeito - o mesmo método que, aliás, permitiu, aos mesmos pesquisadores, a descoberta do gás Neon. É um elemento raro (cerca de 1 ppm da atmosfera), encontrado entre os gases vulcânicos, águas termais e em alguns minerais. Tal como o neon, o criptônio é usado hoje na fabricação de lâmpadas fluorescentes (fluorescentes, aliás, são as roupas dos kryptonianos no conselho que decide o destino de Krypton, na adaptação de Richard Donner, Superman, de 1978).

${ }^{5} \mathrm{O}$ astrofísico Neil deGrasse Tyson, pesquisador e divulgador da ciência, diretor do Planetário Hayden, no American Museum of Natural History de Nova York, e que trabalha também como consultor para a DC Comics, sugeriu que Krypton orbitasse a anã-vermelha LHS 2520, na constelação do Corvo, cerca de 27,1 anos-luz da Terra. O professor Tyson, representando a si mesmo, aparece como personagem em um número da Action Comics (\#14, The New 52, Janeiro 2013), mostrando a Kal-El, através de uma conjunção de telescópios e radiotelescópios em escala mundial, a explosão de seu planeta natal projetada na abóbada do Planetário Hayden: daí podermos inferir a idade de Kal-El no episódio, uma vez que a luz da explosão demorou 27,1 anos para ficar ao alcance dos equipamentos terrestres (Kal-El teria chegado à Terra pegando um atalho através de um buraco-negro, o que deixou a viagem, para ele, muito mais curta). A estranha numeração da Action Comics (\#14, janeiro de 2013, sabendo que a primeira $A C$ foi impressa em junho de 1938) se deve a uma reestruturação radical proposta recentemente pela DC Comics, a chamada reformulação The New 52: a partir de setembro de 2011, todas as histórias dos personagens DC (Batman, Liga da Justiça, Superman, entre outros) foram integralmente reiniciadas, com os respectivos quadrinhos e séries ganhando nova numeração e seus diversos enredos e histórias recriados a partir do zero.

${ }^{6}$ As aventuras de Superman apareceram inicialmente em três revistas DC: Action Comics (a partir do \#1, junho de 1938), Superman (\#1, verão de 1939) e World's Finest Comics (a partir da primavera de 1941), todas publicadas em paralelo (uma história não necessariamente em sinergia com a outra) e, nos seus anos iniciais, com variável periodicidade.

${ }^{7}$ Esta sequência, que contém uma das versões mais conhecidas do mito de origem do Superman, não aparece, como disse acima, na Action Comics \#1 (junho de 1938), nem na primeira revista exclusiva do personagem, Superman \#1 (1939). Começou a ser divulgada, por necessidades comerciais de enredo e adaptação, apenas no final dos anos 1940, na publicação de Superman \#61 (Nov.-Dec., 1949) e na primeira versão cinematográfica do herói feita com atores de carne e osso (The Adventures of Superman, Columbia Pictures, 1948, com Kirk Alyn no papel principal). Como se sabe, a primeira de todas as adaptações de Superman para o audiovisual foi em desenho animado, encomendada pela Paramount Pictures aos estúdios Fleischer (15 episódios, de 1941 a 1942) e, em seu primeiro episódio (The Mad Scientist, lançado em 26 de setembro de 1941), não existe a sequência de despedida. Para a minha geração, a representação mais conhecida deste momento capital da história do personagem é a do início de Superman, o Filme, de Richard Donner, em 1978 (com Marlon Brando e Susannah York nos papéis de Jor-El e Lara); mas a mesma sequência já tinha sido divulgada no primeiro episódio da série cinematográfica da Columbia Pictures de 1948 (Superman Comes To Earth, dirigido por Thomas Carr, com Nelson Leigh como Jor-El e Luana Walters como Lara), e no piloto de Adventures of Superman, série televisiva de 1952 (Superman on Earth, também dirigido por Thomas Carr, com Robert Rockwell e Aline Towne nos respectivos papéis). Todas as animações (já em domínio público) e alguns desses filmes podem ser encontrados no YouTube. A série de 1948 foi lançada no Brasil em DVD. 
atravessa solitária e corajosamente imensos corredores de matéria escura, desviando de asteroides perdidos, ao largo de pálidas constelações bruxuleantes. O casulo entra na atmosfera terrestre e cai numa estrada desolada de Smallville, no Kansas, bem perto onde um simpático casal de fazendeiros de meiaidade, e sem filhos, Martha (ou Mary) e Jonathan (ou John) Kent, conduzia sua velha camionete.

A mitologia do Superman (como boa parte das mitologias, aliás) não é estanque (fenomenologicamente integral ou temporalmente finita), mas uma construção histórica, dinâmica, autoequilibrada e em contínuo processo de mutação. Entretanto, a formulação do mitema "original" clássico é claramente construída sob duas figuras de linguagem (antítese e ironia) e essa configuração é fundamental para o assentamento de Superman em sua caracterização mais específica: não exatamente uma ponte entre o homem e o super-homem (uma linha reta de progressão rumo ao pós-humano, portanto), mas um herói contraditório: um semideus no corpo controlado do bom moço americano do final dos anos 1930, sem hybris e domesticado no respeito à lei e à politesse.

As antíteses estão em todo lugar nessa sintaxe paradoxal e o casulo-espaçonave que lhe serve de casa durante alguns anos no espaço (a única estrutura material kryptoniana que acompanha o Superman e que está presente em todas as versões do mito de origem), por exemplo, é já uma figura significativa. Em primeiro lugar, pelo fato de garantir e reforçar, potencialmente, a continuidade das antíteses presentes em todas as possibilidades de expansão do mitema: o frágil bebê super-humano segue sozinho através do espaço-tempo, mas viaja guarnecido pela força dos cômputos científicos de Jor-El (os próprios cálculos são uma espécie de extensão dos poderes do pai), provenientes de uma ciência milhares de anos à nossa frente. Em seguida, pela natureza singular da situação subtextual: o doravante filho único de Krypton é, sem cometer crime algum, um exilado; pior, um objeto expelido, espécie de secreção, cuspido planeta afora nos estertores de seu fim. Some-se a isso a sonoridade fortemente hebraica (Jerry Siegel, roteirista criador de Superman, era o caçula de imigrantes judeus lituanos) de "kal-el", que poderia significar "amigo [kal] de Deus [el]": a partícula “el” sendo o típico designativo veterotestamentário do anjo ou emissário divino (Rafa-el, Gabri-el etc.). Neste caso, a analogia com a Estrela de Belém e as perícopes neotestamentárias envolvendo Maria, José e Jesus não poderiam ser desprezadas no contexto, os nomes Martha e Jonathan ( $\mathrm{M} \& \mathrm{~J}$ ), duplicando simbolicamente o casal neotestamentário jesuânico ${ }^{8}$. Assim, o casulo com um bebê vagando pelo espaço sideral (um novo útero, onde o herói se desenvolve aprendendo, pela audição, os mais avançados dados científicos de Krypton através da voz de Jor-El), além de uma imagem extremamente poderosa de contraste (a fragilidade contra a imensidão), ganha aqui uma dimensão messiânica plausível, equilibrando a fria ciência kryptoniana (que o envia ao espaço) e a imagem de esperança evangélica vinda dos céus (que boa parte dos terráqueos adora aguardar).

Atravessada essa etapa, o enviado renasce na Terra. Embora na primeira formulação pública (Action Comics \#1, 1938) sua nave "pouse na terra", nas modernas versões cinematográficas ele renasce literalmente na Terra, pois, o casulo rasga o solo como um arado e o pequeno Kal-El brota dele, germinando como uma semente - chegando mesmo a mimetizar, no filme de Richard Donner, o gesto da cruz ao abrir os braços para o casal Kent ${ }^{9}$. Assim, o ciclo mitológico agrário (baseado na morte e na ressurreição), adequado às comunidades agrícolas do meio-oeste americano, se fecha, pois a condição para que Superman exista na Terra é a destruição do seu próprio planeta. Doravante, ao brotar nos

\footnotetext{
${ }^{8}$ Por outro lado, a etimologia de "Kent" (uma forma do inglês antigo cent possivelmente derivada do grego kantion através do latim cantium) tem significado provavelmente topográfico: “coastal district", “land of the hosts or armies", são algumas das hipóteses. ${ }^{9}$ Smallville é uma comunidade rural, utilizada como lugar da infância de Superman pela primeira vez em Superboy \#2 (maio de 1949). De localização indeterminada nas variantes anteriores do mitema, a partir do filme de 1978 foi definida como parte do condado de Lowell, no Kansas, meio-oeste americano.
} 
campos, como um presente para um casal infértil de meia-idade, seu passado extraterrestre ficará definitivamente para trás ${ }^{10}$ - muito embora o desenvolvimento comercial do personagem, e do mundo dos quadrinhos como um todo, tenha permitido criar, desde então, revisionismos e situações paralelas ou complementares das mais diversas ordens ${ }^{11}$.

O mitema original, porém, revisto pelas versões posteriores, vai acrescentando outros elementos antitéticos, expandindo as ironias em dimensões bem mais complexas. Por exemplo, no lamento materno de Lara-El, antecipando as dificuldades de Kal-El, que é estruturado sob um discurso denegatório tipicamente colonizador. A Terra, esta Terra da salvação (banhada pelo Sol amarelo, ela dará ao pequeno Kal-El, ao que tudo indica, todos os seus inacreditáveis poderes), está povoada por humanos tecnologicamente inferiores (que muito em breve se descobrirão, com a presença do Superman, biologicamente inferiores, e, ato contínuo, também teologicamente deslocados de seu lugar especial e único no Universo ${ }^{12}$ ). É neste lugar, bom e hostil, dominado por estes seres triplamente inferiores (os mesmos que ele, doravante, terá por missão zelar e ajudar), os terráqueos, que Kal-El será recebido como um forasteiro, um indesejado, um outcast. Cada dolorosa previsão de Lara em seu famoso lamento de adeus, pressentindo instintiva e maternalmente os perigos que Kal-El terá de enfrentar, será respondida, porém, com confiança estoica por Jor-El: e a ironia antitética se redobra, pois o roteiro aqui se utiliza de outro clássico recurso narratológico da épica e do trágico, o da prolepse (ou antecipação) ${ }^{13}$.

\footnotetext{
10 Como disse acima, a narrativa que descreve com detalhes as origens extraterrestres do Superman é, essencialmente, um mitema desenvolvido posteriormente, no último quarto da Golden Age dos quadrinhos americanos. Até então, o que se sabia da história de Kal-El começava, usualmente (como na primeira página da Action Comics \#1, 1938), com a imagem do casulo/foguete já no espaço sideral, escapando miraculosamente da explosão de Krypton, sendo encontrado, um ou dois quadros depois, pelos Kent: os acontecimentos anteriores sendo inferidos apenas por detalhes esparsos: "In the Golden Age, Superman was unaware initially of his true origins; in Superman \#61, Superman discovered the existence of Krypton for the first time and learned of his Kryptonian heritage. He later encountered other survivors prior to Kara's arrival in the form of three criminals, U-Ban, Kizo and Mala, who were exiled by his father before Krypton's destruction." (Verbete Krypton (comics) in Wikipedia.org).

${ }^{11}$ Superman, por exemplo, teve seus anos adolescentes em Smallville contados de maneira independente da sua história original - neste caso, ele será o Superboy, cuja primeira aparição, também criada por Siegel e Schuster, aconteceu na More Fun Comics \#101, de 1944. Esses acréscimos, imprevistos na primeira versão do seu mito de origem, criaram, com suas inerentes complexidades, graves problemas de sincronização histórica entre personagens e enredos - e não apenas no caso do Superman, mas de quase todos os principais heróis da Golden Age. Isso levou os roteiristas DC a criarem, aos poucos, a noção de mundos paralelos, onde o desenvolvimento pulverizado de seus protagonistas, em histórias por vezes contraditórias, se tornassem relativamente plausíveis para os fãs. Foram criados universos e Terras diferentes (Terra 1, Terra 2 etc., as chamadas Terras Paralelas), mas em tudo iguais às referências físico-cósmicas que conhecemos (em outras palavras, "mundos possíveis", que muito devem a certas construções da lógica contrafactual contemporânea), diante das quais as aventuras anteriores passaram a se reportar e nas quais as aventuras do presente narrativo passaram a transcorrer, sem aviso preliminar. Assim, tornou-se mais fácil explicar, por exemplo, por que razão Lanterna Verde e The Flash - que nos anos 1940 eram vividos por alter-egos chamados, respectivamente, Alan Scott e Jay Garrick -, ressurgiram nos quadrinhos dos anos 1960, após um período de ostracismo editorial, como Hal Jordan e Barry Allen. Ou por que personagens mortos por um determinado herói, em determinado número de uma revista do passado, voltavam posteriormente à ativa nas aventuras de outro herói (um problema porque, aparentemente, tudo se passa no mesmo presente histórico diegético, que é normalmente contemporâneo ao presente histórico das publicações e do público). Como se pode depreender, a intensificação desses mundos possíveis e paralelos, inicialmente uma saída engenhosa dos roteiristas, tornou o universo DC cada vez mais complexo, a ponto de torná-lo, se tomado no contexto integral das publicações, no fio do tempo, incompreensível. A primeira tentativa de fazer tabula rasa nesse emaranhado de situações incompatíveis foi a série Crise nas Infinitas Terras (ciclo de 12 revistas, 1986), onde um gigantesco conflito de dimensões multicósmicas pôs termo às disparidades mais urgentes desses universos paralelos (bom resumo no verbete homônimo da Wikipedia.org). A mais recente, chamada reformulação The New 52 - desta vez não uma tentativa de harmonização das múltiplas diegeses dos mundos onde habitam os personagens, mas simplesmente um ato editorial e comercial - teve lugar em setembro de 2011 (cf. nota 5 acima).

$12 \mathrm{O}$ que sempre pode ser revisto, claro, pois qualquer teologia também é provisória e revisionista - quando lhe convém.

${ }^{13}$ Lara: "But why Earth, Jor-El? They're primitives, thousands of years behind us". Jor-El: "He will need that advantage to survive. Their atmosphere will sustain him. He will defy their gravity. He will look like one of them". Lara: "He won't "be" one of them". Jor-El: "No. His dense molecular structure will make him strong". Lara: "He'll be odd. Different". Jor-El: "He'll be fast. Virtually invulnerable". Lara: "Isolated. Alone". Jor-El: "He will not be alone. He will never be alone". Uso aqui, claro, os diálogos de Superman, the Movie, de Richard Donner (1978).
} 
Mas por que a Terra, afinal? Por que justamente a Terra dos primitivos? Jor-El é taxativo: "Ele precisará dessa vantagem para sobreviver". Simétrica ou paralela a Krypton, a Terra permite inferências e constatações plausíveis tanto aos personagens da história (no subtexto) quanto a nós, leitores/espectadores. Além das relativas similitudes físicas e geofísicas (atmosfera, gravidade, solo rochoso etc.), a Terra possui uma sociedade. Embora diferente na condição propriamente geopolítica (Krypton não é um país, mas um planeta, ou melhor, ao que tudo indica, um planeta-país, e os discursos de Lara e de Jor-El tratam a Terra da mesma maneira, consideram-na como uma única e mesma coisa, para além das fissões políticas nacionais, os conflitos armados, o colonialismo ou qualquer outra banalidade revoltante), a Terra lhes replica uma estrutura perfeitamente familiar. Ainda que os humanos sejam, em tudo, milhares de anos inferiores aos habitantes de Krypton, a Terra é, ironicamente, um planeta com criaturas que também vivem sob estruturas sociais organizadas; corpus político e administrativo; conselhos deliberativos; cientistas; malfeitores, revolucionários, arrogância de classe. Sim, os terráqueos podem ser inferiores (biologicamente, tecnologicamente) aos kryptonianos, mas eticamente não são muito diferentes dos conselheiros imbecis que, como acontece entre os políticos da Terra, definem catastroficamente os rumos dos seus respectivos planetas (e não raro, Superman terá de lidar, em suas aventuras, com situações muito similares a de Jor-El diante do Conselho de Krypton) ${ }^{14}$.

Subúrbio das galáxias ${ }^{15}$, lugar onde se depositam todas as esperanças da continuidade de Krypton, a Terra é, assim, um locus profético mas cientificamente mensurável, em vista do qual o cientista pode, no momento em que põe seu filho no casulo, 27 anos antes, prever o inexorável e extraordinário futuro do seu jovem kryptoniano. Essa esperança é antitética, paradoxalmente ativa e passiva. Visto pela mãe, KalEl, é um pobrezinho indefeso, um sofredor: "ele não será um deles", "será um deslocado, um diferente", diz ela. Mas, visto pelo pai, Kal-El é um verdadeiro herói conquistador, poderosamente equestre em seu casulo como o Napoleão de David diante dos Alpes: "A atmosfera deles o sustentará; ele vai desafiar sua gravidade"; "sua densa estrutura molecular o fará forte"; "ele será rápido; virtualmente invulnerávep".

É assim que o lamento de despedida retroalimenta o paradoxo da esperança kryptoniana diante de Kal-El em um autêntico enredo subliminar do discurso colonial clássico - dimensão que só foi mais decisivamente explorada nas últimas franquias de Superman para o cinema (particularmente em Man of Steel, de Zack Snyder, 2013) ${ }^{16}$. Obviamente, não se trata de discurso colonial no sentido explícito de propaganda, mas dos topoi retóricos que são inerentes à experiência colonial: a tópica do fogo civilizador trazido pelo estrangeiro ("o selvagem" do invadido versus "o evoluído" do invasor), intrinsecamente ligada a uma forte idealização do contexto ("o mundo decadente" do invasor versus "o paraíso" do invadido), levando não raro à insubstancialização pura e simples do real (a alteridade que vai se conquistar vista como um sonho e/ou algo estragado por aqueles que a ocupam concretamente em seu quotidiano) e assim por diante ${ }^{17}$. Além disso, a caracterização da cena original da saída de Kal-El de Krypton como uma possibilidade garantida por uma Ciência superior (ainda que alienígena trata-se mesmo lá, em Krypton, claro, da Ciência, pois a Ciência, dizem os roteiristas, não é histórica, humana ou alienígena, é uma só: nós é

\footnotetext{
${ }^{14}$ A apocalíptica antropocênica terráquea não se assemelha propriamente ao iminente cataclismo kryptoniano. Nas primitivas versões do mitema de origem (na verdade, até muito recentemente), este acontece por questões alheias à exploração extrativista de Krypton pelos kryptonianos - em Superman, \#61, 1949, Jor-El diz a Lara: "I told them that the core of our planet is uranium, which for untold ages has been building a cycle of chain-reactions..."). A destruição de Krypton só será relida como uma espécie de kryptonianoceno (neste caso, devido à exploração desenfreada do núcleo do planeta em busca de recursos energéticos) na adaptação de Zack Snyder (Man of Steel, 2013), bancada pela Warner Bros., com roteiro de David S. Goyer.

15 "Terra. Subúrbio das galáxias" (Murilo Mendes, Convergência).

${ }_{16}$ É importante lembrar que, à época da primeira aparição de Superman (junho de 1938), o Anschluss teuto-austríaco já aconteceu e a entrada de Hitler na Polônia, iniciando (como tradicionalmente se aceita) a $2^{a}$ Guerra Mundial, não está longe.

${ }^{17}$ Cf. SPURR, David. The Rhetoric of Empire: Colonial Discourse in Journalism, Travel Writing, and Imperial Administration, Duke University Press, 1993.
} 
que ainda não chegamos lâ) também reforça esse quadro retórico de tipo colonial: o primitivo (invadido) versus o tecnologicamente desenvolvido (invasor). O fato daquele que invade ser considerado e descrito, paradoxalmente, como vítima (potencial ou não) do mundo invadido - assim como as necessárias benesses que o invadido forçosamente (com duplo sentido) receberá do invasor, o que justifica a invasão em si amplificam ainda mais os mecanismos desse discurso ${ }^{18}$.

Os efeitos da aparição do Superman diante da humanidade são também antitéticos: explicitamente, alegria profunda; ocultamente, o maior dos horrores. A descoberta de um homem vitruviano real, caído das estrelas, eternamente jovem, de corpo musculoso perfeito e defensor do american way, não pode fazer esquecer que, com ele, o primado maior do sistema WASP caiu por... terra (e a expressão aqui tem, obviamente, duplo sentido): por mais simpático, branco e defensor desse sistema, a mera existência do Superman arrasa com todas as possibilidades do primado humano geocêntrico do cristianismo, em particular do nacional-cristianismo americano médio - que transforma a língua inglesa em uma constante interplanetária e a América em epicentro ou Nova Jerusalém de todas as galáxias ${ }^{19}$. Uma vez que, na prática, os pontos dogmáticos centrais do cristianismo ficam sempre de fora de todas as suas aventuras (Superman já lutou com Atlas, Hércules e Sansão ${ }^{20}$, mas nunca foi batizado, nem jamais se questionou sobre a divindade de Cristo), é por conta de seu engajamento imediato com o modo de vida americano, quer dizer, ao assumir o american way como seu verdadeiro credo, que Superman transmuta a América em uma nova humanidade. E para que não haja dúvidas de sua perfeita integração com o futurismo industrial (e sua suprassunção conservadora), a vinheta clássica das adaptações televisivas é construída com Superman ultrapassando os estereótipos da grandeza americana em seu moderno meio-ambiente capitaloceno: "mais rápido que uma bala, mais poderoso que uma locomotiva, capaz de pular arranha-céus com um único salto".

Desde a sua primeira aparição pública (ao salvar uma inocente da cadeira elétrica invadindo, de modo nada polido, a casa do governador de Metrópolis com uma confissão escrita da verdadeira assassina - provando não ser contra a pena de morte, apenas contra a injustiça de uma condenação equivocada ${ }^{21}$ ), Superman jamais deixou de assentir com as instituições politico-jurídicas americanas: "ainda bem que, aparentemente, ele está do nosso lado", diz, aliviado, o governador diante de sua incrédula equipe ${ }^{22}$. O que mais chama atenção é o fato desse campeão da lei e da ordem ser, em última análise, um imigrante ilegal. Apesar de também percorrer perigosamente os desertos (intergalácticos) até chegar à Terra Prometida, trata-se, contudo, de um imigrante ilegal que não poderia ser facilmente rechaçado pelos trâmites usuais da alfândega. Em Man of Steel (Zack Snyder, 2013), o Exército, desconfiado, tenta vigiá-lo, mas é ele mesmo quem diz: "Fui criado no Kansas, general. Mais americano impossivel”. De fato, gozando dessa situação confortável durante muito tempo, foi apenas tardiamente que ele renunciou à cidadania (e à agenda geopolítica) americana ${ }^{23}$. Mas a superação da América como uma pós-humanidade está ali, fermentando em segredo através dele, e paradoxalmente atrela-se ao fato desse imigrante ilegal de Krypton sempre

\footnotetext{
18 "Expansionist $W$ estern medical discourse in colonizing contexts has been obsessed with the notion of contagion and hostile penetration of the healthy body, as well as of terrorism and mutiny from within. This approach to disease involved a stunning reversal: the colonized was perceived as the invader." (HARAWAY, Donna. Simians, Cyborgs, and Women. The Reinvention of Nature, Routledge, 1991, p. 223). Quanto a essa logística de inversão, a do invasor visto como vítima, ver OTIS, Laura. Membranes: Metaphors of Invasion in Nineteenth-Century Literature, Science, and Politics. John Hopkins University Press, 2000.

19 Talvez a "Terra" pensada por Jor-El e Lara no mitema de origem, seja, afinal, apenas a "América".

${ }^{20}$ Action Comics \#320, 1965.

21 Action Comics \#1, 1938.

22 Action Comics \#1, 1938.

23 "I intend to speak before the United Nations tomorrow and inform them that I am renouncing my U.S. citizenship. I'm tired of having my actions construed as instruments of U.S. policy. Truth, justice, and the American way it's not enough anymore" (Action Comics \#900, abril de 2011).
} 
viver escondido, encriptado: se ser imigrante ilegal, mas branco e adotado por brancos, parece ser a chave do sucesso de sua perfeita assimilação (a invisibilidade social é o primeiro dos seus poderes), trabalhar para aqueles que o adotaram tão gentilmente seria como que o pagamento ideal esperado (talvez mesmo exigido) por qualquer americano ${ }^{24}$. Por outro lado, se Kal-El pôde passar todo esse tempo (entre a infância até sua primeira aparição, já adulto) entre nós sem ser percebido, e ainda permanecer incógnito circulando nas ruas de Metrópolis através de Clark Kent, quantos outros poderiam existir virtualmente despercebidos dos sistemas panópticos de controle disponíveis? Isso pouco importa agora: se os forasteiros intergalácticos forem virtuosos como ele (quer dizer, aceitando o american way), o sistema só terá a lucrar em absorvê-los. Se contrários a esses valores, Superman estará lá para assegurar seu aniquilamento. Visto desse modo, é como se, por conta de suas fantásticas habilidades, Superman se tornasse automaticamente apto para o green-card: e nós sabemos que, para ser bem-quisto pelos alfandegários, o imigrante precisa ter certos poderes (ser um famoso artista de cinema, um investidor EB5, um especulador da bolsa de valores com uma cartela de alguns milhões de dólares e assim por diante).

Mesmo seu desenvolvimento pessoal e afetivo é paradoxal, apesar de se enquadrar perfeitamente no cenário mítico da sala de estar americana: ele é o filho obediente, dedicado aos pais e aos estudos, trabalhador honestíssimo, reservado, com elevado senso moral etc., como se vivesse congelado em um episódio de Os W altons. Mas, neste caso, curiosamente, as funestas lamentações de Lara-El no mito de origem, a respeito da Terra ser uma perda (um atraso) e não um ganho para o seu rebento, ganham, na caracterização propriamente terráquea de Clark Good Guy Kent, uma assertiva concreta - ainda que sutil. Em Superman \#61 (1949), Kal-El finalmente entende sua origem, pela primeira vez consegue traçar o lastro de sua história pessoal. Investigando os poderes de uma gema misteriosa (que depois ganhará o mortífero nome de kryptonita) usada por um vilão, viaja à velocidade da luz pelo espaço-tempo no rastro de um meteorito (seus poderes estão sempre sendo descobertos por ele mesmo) e chega, desmaterializado pelas leis einsteinianas, até Krypton, no passado, no exato momento de sua própria partida, na cena que será repetida, doravante, como seu mito de origem. Nessa forma fantasmagórica ${ }^{25}$, mas sem se dar conta de estar presenciando sua própria história, vê sua verdadeira família; vê a si próprio, ainda bebê, sendo posto no casulo; testemunha a explosão de Krypton; acompanha o casulo em sua jornada e chega à Terra, sempre no passado, na velha estrada de Smallville, diante da camionete de seus pais adotivos ${ }^{26}$. Mas, na medida em que compreende de onde veio, entendemos que a percepção materna de Lara estava certa: o exílio forçado separou radicalmente Kal-El da evolução da infância e da adolescência kryptonianas ordinárias. Na forma fantasmagórica do espaço-tempo em Krypton, Superman pôde ver as proezas da tal "advanced civilization and people of great intelligence and physical perfection"27, "milhares de anos à nossa frente". Embora feito com matéria 100\% kryptoniana, ele, por exemplo, jamais dominou as Ciências Aplicadas aos cinco anos de idade, como qualquer criança normal de Krypton ${ }^{28}$. Assim, enquanto encarnado em Clark Kent, quer dizer, enquanto terráqueo, Kal-El foi paulatinamente reduzido, pela habilidade controladora de seus pais adotivos terrestres, a uma metáfora do americano médio, parvo, abestalhado, inábil (na escola, por exemplo, seria impossível machucá-lo fisicamente, mas o bullying moral é mais

\footnotetext{
${ }^{24}$ Como o casal Kent nunca foi à polícia dar parte do rebento que encontraram na estrada, há de se considerar que Kal-El tenha sido vítima, em algum nível, de uma espécie de sequestro - ou de abdução - pelos terráqueos.

25 "Editor's note: Superman is invisible to these people because he is not of their time and doesn't exist for them. He can only view them as he would a silent movie, but he can read lips." (Superman, \#61, 1949, p. 8). Esse recurso ex machina (no caso, a "nota do editor" dentro de um quadrinho) não é raro como justificativa "científica" nas histórias da Golden Age.

26 "Now I understand why I'm different from earthmen! I'm not really from Earth at all. I'm from another planet, the planet Jor-El called Krypton”. (Superman, \#61, 1949, p. 8).

27 Superman, \#61, 1949, p. 8.

${ }^{28}$ Em Krypton, Superman se depara com uma mãe preocupada porque "Junior is past five and he does not yet know his engineering?". Ao que sua forma fantasma exclama: "Engineering... at age five??" (Superman, \#61, 1949, p. 8).
} 
eficiente que toda a sua superforça, e nisso os estudantes humanos são mestres). Sem a devida opulência cultural e material que sempre caracterizou a crosta paradigmática dos povos conquistadores grecoromanos ou árabes, Clark Kent é uma expressão do average Joe, o típico idiota que, eventualmente, se sente dono do mundo - coisa que Kal-El poderia reivindicar, natural e tranquilamente (na lógica otimista de Jor-El), se não fosse criado e domesticado justamente como o boa praça e almofadinha Clark Kent (cumprindo a profecia negativa de Lara-El).

Deste modo, podemos voltar à cena inicial. A intrínseca relação entre o expelido (de Krypton) e o renascido (na Terra) não poderia ser mais fortuita. Ao observar o mitema que resume essa situação originária, um leitor grego contemporâneo ao Pseudo-Aristóteles, por exemplo, que tivesse o número \#1 da Action Comics diante dos olhos, poderia perfeitamente inferir que o jovem ocupante do casulo

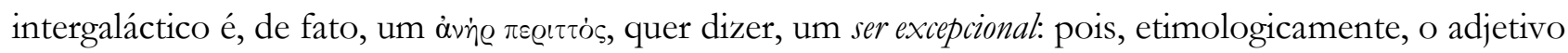

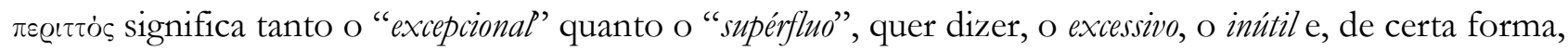
o excremencial ${ }^{2}$. O bebê expelido em seu casulo (metáfora plausível do renascimento uterino ou da secreção), residual sobrevivente de Krypton (transcrição latina que o leitor grego do Pseudo-Aristóteles

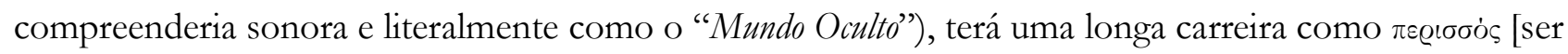
excepcional] terrestre - e será codinominado, de maneira metapoética pelos terráqueos (que lhe são em tudo inferiores)... Superman ${ }^{30}$. Bom... tudo isso não é mal, mas... que Super é esse que põe uma cueca vermelha por cima das calças?

29 “(...) o homem excepcional (perittos) é o homem do resíduo (perissoma)." (PIGEAUD, Jackie. "Apresentação” in ARISTÓTELES, O Homem de Gênio e a Melancolia, p. 18).

30 As primeiras referências à ideia de "super-humano" vêm, não de Nietzsche (Übermensch) mas do grego helenístico:

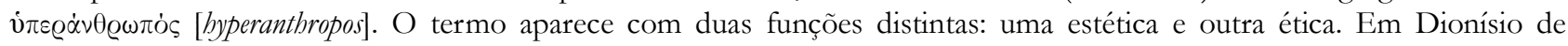
Halicarnasso (sec. I a.C.), sua valência é estética: "Enquanto eles estavam apresentando estes e muitos outros argumentos igualmente pesados e incontestáveis, derramando um fluxo de compaixão sobre os infortúnios da menina, todos os outros que ouviram suas palavras sentiram compaixão por conta de sua beleza - pois, apesar de vestida em trajes sórdidos, olhando para o chão, e escurecendo o brilho de seus olhos com lágrimas, ela

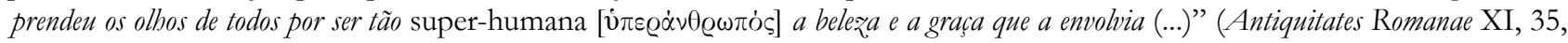
2, 4, Loeb Classical, p. 115). E também em Luciano de Samósata (sec. II d.C.), mas desta vez sua valência é ética: "Ouça, respeitável deusa. Lá em cima, eu me hospedava junto a este tirano. Via perfeitamente tudo o que ele fazia, e o tomava às vezues como semelhante aos deuses. Invejava sua felicidade, vendo a flor de sua púrpura, seu numeroso séquito, seu ouro, seus cordões carregados de pedras preciosas, seus móveis suspensos por pés de prata; o cheiro das suas refeições [era tão bom que] me fą̧ia mal: em uma palavra, eu o considerava acima do

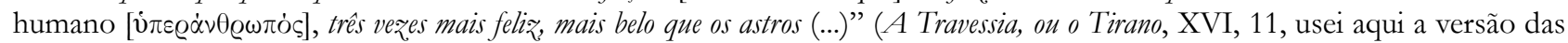
CEuvres Complètes, Tome 1, p. 246). Ver BARKMAN, Adam. "Superman. From Anti-Christ to Christ-Type". In WHITE, Mark D. (ed.) Superman and Philosophy: What Would the Man of Steel Do?. Wiley-Blackwell, 2013, pp. 111-120. 


\section{REFERÊNCIAS}

(Pseudo-)ARISTÓTELES. O Homem de Gênio e a Melancolia. Ed. PIGEAUD, Jackie. Rio de Janeiro: Lacerda Editores, 1998.

BARKMAN, Adam. "Superman. From Anti-Christ to Christ-Type”. In WHITE, Mark (ed.) Superman and Philosophy: What Would the Man of Steel Do?. Wiley-Blackwell, 2013, pp. 111-120.

HARAWAY, Donna. Simians, Cyborgs, and Women. The Reinvention of Nature. New York: Routledge, 1991. OTIS, Laura. Membranes: Metaphors of Invasion in Nineteenth-Century Literature, Science, and Politics. Baltimore: John Hopkins University Press, 2000.

SIEGEL, Jerome \& SHUSTER, Joe. Superman. In: Action Comics \#1, 1938. New York: DC Comics, 1938.

SIEGEL, Jerome \& SHUSTER, Joe. Superman returns to Krypton. In: Superman, \#61, 1949. New York: DC Comics, 1949.

SPURR, David. The Rhetoric of Empire: Colonial Discourse in Journalism, Travel Writing, and Imperial Administration. Durham: Duke University Press, 1993.

Recebido em: 14 de outubro de 2020. Aprovado em: 10 de novembro de 2020. 